\title{
Association between housing environment and depressive symptoms among older people: a multidimensional assessment
}

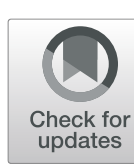

\author{
Yuan Chen, Ping Yu Cui, Yi Yang Pan, Ya Xing Li, Nuremaguli Waili and Ying Li
}

\begin{abstract}
Background: Depression is a common mental disorder among older people. This study aimed to assess the association between housing environment factors and depressive symptoms among older people using a multidimensional assessment method.
\end{abstract}

Methods: The study uses a population-based cross-sectional design. A total of 950 participants aged $\geq 60$ years were selected using a complex multistage sampling design from 22 locations in China. All data were collected using questionnaires by face-to-face interviews. A total of 938 participants were included in the analysis, and 17.1\% of males and $23.1 \%$ of females were identified as having depressive symptoms. The depressive symptoms were assessed using the 15-item Geriatric Depression Scale. The housing environment was assessed on the basis of four dimensions: physical, social, psychological, and cognition and physical function. Cumulative logistic regression analysis was used to evaluate the association between housing environment and depressive symptoms.

Results: The Cochran-Armitage trend test showed that the depressive symptom scores were linearly negatively associated with self-assessed housing environment, living arrangement, life satisfaction, and other physical environment factors and linearly positively associated with cognitive and physical function scores. The results of cumulative logistic regression analysis showed that the housing environment was significantly associated with depressive symptoms. The participants' self-assessed housing environment was strongly associated with the levels of depressive symptom scores, and the odds ratio was 3.47 ( $95 \% \mathrm{Cl}, 1.14-10.82, P=0.003$ ).

Conclusion: The housing environment was significantly associated with depressive symptoms. Our results suggest that multi-dimensional assessment in the housing environment may be an effective way to develop intervention strategies of depressive symptoms among older people.

Keywords: Depressive symptoms, Housing environment, Multidimensional assessment, Cumulative logistic regression analysis, Cross-sectional study

\section{Background}

With the growing population of older people worldwide, health problems and challenges for individuals, society, and public health systems are increasing. A common concern is that the prevalence of depression among

\footnotetext{
*Correspondence: ying_li@zju.edu.cn

Department of Social Medicine, School of Public Health, Zhejiang University, 866 Yu-hang-tang Road, Zhejiang 310058, Hangzhou, China
}

older people increases with increasing life expectancy [1, 2]. The prevalence ranges from 6 to $80 \%$ in different countries and regions of around the world [3, 4].

As an important mental health problem, depression is a major cause of global disability and suicide and may be associated with cardiovascular diseases and mortality through a complex and potential mechanism of biological crosstalk [5-7]. Severe depression impairs the

(c) The Author(s). 2021 Open Access This article is licensed under a Creative Commons Attribution 4.0 International License, which permits use, sharing, adaptation, distribution and reproduction in any medium or format, as long as you give appropriate credit to the original author(s) and the source, provide a link to the Creative Commons licence, and indicate if changes were made. The images or other third party material in this article are included in the article's Creative Commons licence, unless indicated otherwise in a credit line to the material. If material is not included in the article's Creative Commons licence and your intended use is not permitted by statutory regulation or exceeds the permitted use, you will need to obtain permission directly from the copyright holder. To view a copy of this licence, visit http://creativecommons.org/licenses/by/4.0/ The Creative Commons Public Domain Dedication waiver (http://creativecommons.org/publicdomain/zero/1.0/) applies to the data made available in this article, unless otherwise stated in a credit line to the data. 
lives of older people more than serious medical illnesses, and treatment of depression has the potential to improve their lives in spite of other medical comorbidities $[8,9]$.

The causes of depression are complex and incompletely understood. Depression is often considered as a result of medical illness, but social, behavioral, and psychological factors are commonly considered as important risk factors for depressive disorders [10-12]. Many studies have consistently found that behavioral and psychosocial factors, such as alcohol and substance abuse, smoking, sleep disturbance, physical inactivity, unhealthy eating habits, and stressful events, and sociodemographic factors, such as low income, unemployment, low education level, and low social support, are mostly associated with an increased risk of depressive behaviors [13-16]. In addition, chronic diseases, bereavement, retirement, social isolation, and loss of income are major risk factors for depression among older people [17].

Recently, the association between environmental factors and depression has attracted increasing interest. Previous studies have shown that physical, social, and psychological environments may affect an individual's mental health and also suggested that the environment may play a particularly important role in the mental health of older adults compared with younger adults [18]. Moreover, the number of care homes has decreased as more older people are choosing to live at home. These people expect to spend as much time at home as possible in their last years. As a result, the housing environment has become more important to them.

Our understanding of the health effects related to the housing environment has evolved over the past two decades. During this period, the focus of studies on the housing environment has shifted from indoor air constituents such as fuel use to accessible housing [19]. Older people living in accessible homes and independently performing daily activities were found to have better well-being and suffer less from depressive symptoms [20]. However, studies focusing on depressive symptoms and the housing environment generally pay little attention to other environment factors or have weak research designs, often lacking control for confounding variables. In addition, previous studies have evaluated the association between housing environmental exposure and the risk of mental disorders in the general population. Studies have shown that older people spend $90 \%$ of their time indoors and have a longer period of housing environmental exposure compared with the general population. Therefore, the previous evaluation results might have underevaluated the situation of older people.

However, the pathogenesis of depression in older people is complex and not fully clear. Environmental psychology is a field of applied social psychology that studies the relationship between environment and human psychology and behavior. According to systematic theory, the natural environment and social environment are unified, and both have an important influence on behavior. Therefore, we hypothesized that depressive symptoms are related to the housing environment. The present study aimed to assess the association between housing environment factors and depressive symptoms among older people by using a multidimensional assessment method.

\section{Methods}

\section{Sampling procedure}

The study was based on the "Accessibility Evaluation of Health-Related Resources for the Elderly" project, a cross-sectional design that aimed to assess the association between housing environment and depressive symptoms among older people. A total of 950 general residents aged $\geq 60$ years were selected using a multistage sampling design. Sampling was conducted in 22 locations of four provinces (Zhejiang, Heilongjiang, Xinjiang, and Sichuan) in China. We excluded subjects who were unable to complete the questionnaire. All participants provided written informed consent before participation in this study. The study was approved by the institutional review board at the School of Medicine, Zhejiang University.

\section{Sample description}

The characteristics of the study participants by sex are described in Table 1. Among them, $41.7 \%$ were male, and $58.3 \%$ were female. The participants had an average age of 68.5 years, and $38.0 \%$ of the participants were over 70 years of age. Approximately $24.1 \%$ of women reported that they had a lower level of education and completed only 6 years or less of education. Men reported higher frequency of smoking and drinking than women, and women reported that they had higher levels of physical activity than men. More than $67.0 \%$ of participants reported that they had one or more chronic diseases. Approximately $17.1 \%$ of men and $23.1 \%$ of women had a depressive symptom score greater than or equal to 5 points.

\section{Information collection \\ Questionnaires}

Data were collected through questionnaires via face-toface interviews. The interviews were conducted by investigators in the home and community. The questionnaires consisted of nine parts, including 428 items. The main contents included the following aspects: demographic characteristics, general health status and behavior habits, medical resources, community health service resources, psychological resources, environmental resources, and activities of daily living assessment. The interviews took 
Table 1 Characteristics of study participants by gender in the study

\begin{tabular}{|c|c|c|c|c|c|c|}
\hline \multirow{2}{*}{$\begin{array}{l}\text { Variable } \\
\text { categories }\end{array}$} & \multicolumn{2}{|c|}{ Men $(N=391)$} & \multicolumn{2}{|c|}{ Women $(N=547)$} & \multicolumn{2}{|c|}{ All $(N=938)$} \\
\hline & $\bar{n} \%$ & & $\bar{n} \%$ & & $\overline{n \%}$ & \\
\hline \multicolumn{7}{|c|}{ Age (yr.) } \\
\hline $60-69$ & 233 & $(59.6)$ & 346 & $(63.2)$ & 579 & $(61.7)$ \\
\hline 70-79 & 135 & $(34.5)$ & 157 & $(28.7)$ & 292 & (31.1) \\
\hline$\geq 80$ & 23 & (5.9) & 44 & (8.1) & 67 & $(7.2)$ \\
\hline \multicolumn{7}{|c|}{ Education levels (yr.) } \\
\hline $0-6$ & 45 & $(11.5)$ & 132 & $(24.1)$ & 177 & $(18.9)$ \\
\hline $7-9$ & 166 & $(42.5)$ & 191 & (34.9) & 357 & (38.1) \\
\hline $10-12$ & 98 & $(25.1)$ & 120 & $(22.0)$ & 218 & $(23.2)$ \\
\hline $13+$ & 82 & $(20.9)$ & 104 & $(19.0)$ & 186 & $(19.8)$ \\
\hline \multicolumn{7}{|c|}{ Individual income } \\
\hline$¥ 0$ to 1999 & 235 & $(60.1)$ & 319 & $(58.3)$ & 554 & $(59.1)$ \\
\hline$¥ 2000$ to 3999 & 88 & $(22.5)$ & 155 & $(28.3)$ & 243 & (25.9) \\
\hline$¥ 4000$ and Over & 68 & $(17.4)$ & 73 & $(13.4)$ & 141 & $(15.0)$ \\
\hline \multicolumn{7}{|c|}{ Marital status } \\
\hline Married & 354 & $(90.5)$ & 400 & $(73.1)$ & 754 & $(80.4)$ \\
\hline Non-married & 37 & $(9.5)$ & 147 & $(26.9)$ & 184 & (19.6) \\
\hline \multicolumn{7}{|c|}{ Smoking status } \\
\hline Yes & 120 & $(30.7)$ & 8 & $(1.5)$ & 128 & $(13.7)$ \\
\hline No & 271 & $(69.3)$ & 539 & $(98.5)$ & 810 & (86.3) \\
\hline \multicolumn{7}{|c|}{ Alcohol use } \\
\hline Yes & 151 & $(38.6)$ & 41 & $(7.5)$ & 192 & (20.5) \\
\hline No & 240 & $(61.4)$ & 506 & $(92.5)$ & 746 & $(79.5)$ \\
\hline \multicolumn{7}{|c|}{ Regular physical activity } \\
\hline Yes & 136 & $(34.8)$ & 239 & $(43.7)$ & 375 & $(40.0)$ \\
\hline No & 255 & $(65.2)$ & 308 & $(56.3)$ & 563 & $(60.0)$ \\
\hline \multicolumn{7}{|c|}{ Chronic disease status } \\
\hline Yes & 263 & $(67.3)$ & 365 & $(66.7)$ & 628 & $(67.0)$ \\
\hline No & 128 & $(32.7)$ & 182 & $(33.3)$ & 310 & (33.0) \\
\hline \multicolumn{7}{|c|}{ Time before falling asleep (min) } \\
\hline$\leq 10$ & 124 & $(31.7)$ & 157 & $(28.7)$ & 281 & $(30.0)$ \\
\hline $11-29$ & 59 & $(15.1)$ & 105 & $(19.2)$ & 164 & $(17.5)$ \\
\hline $30-59$ & 134 & $(34.3)$ & 171 & (31.3) & 305 & (32.5) \\
\hline$\geq 60$ & 74 & $(18.9)$ & 114 & $(20.8)$ & 188 & (20.0) \\
\hline \multicolumn{7}{|c|}{ Depression score (points) } \\
\hline$<5$ & 324 & $(82.9)$ & 421 & $(76.9)$ & 745 & (79.4) \\
\hline $5-9$ & 54 & $(13.8)$ & 107 & $(19.6)$ & 161 & $(17.2)$ \\
\hline$\geq 10$ & 13 & (3.3) & 19 & (3.5) & 32 & (3.4) \\
\hline
\end{tabular}

approximately 45-60 min to complete for most of the participants. Content validity of the questionnaire is established through a panel of six expert judges. Data were obtained from a Likert-type rating scale. The content validity index on the levels of items were from 0.90 to 1.00 , the content validity index of average scale level was 0.98 and the content validity ratios were from 0.86 to 1.00. Before the formal investigation, we produced a preliminary survey to verify the validity of the questionnaire. We computed the total sample size required for this work based on the empirical study and the events per variable method.

The general characteristics of participants, including age, gender, ethnicity, income, education level, selfreported chronic disease status, disease history, daily habits, and physical activity level, were recorded. Environmental resources were identified from housing and surrounding housing environments. The exposure to housing environment was assessed in terms of four aspects: physical, social, psychological, and cognition and physical function.

\section{Housing environment}

The physical environment of the house was assessed by using a self-assessment instrument. The psychological and cognition environment and social environment were measured using two instruments. These instruments have been proven to be valid and reliable in previous study [21-23]. The physical environment was measured using the following questions: "Is there enough sunlight in your house?" "Is your house well ventilated?" The responses were categorized as "yes" or "no." "How many square meters is your house?" "How long have you lived in your present house?" The participants were also asked about their use of shower and heating.

The social attributes of the housing environment were measured using the living arrangement and neighborhood communication. "Who do you live with right now" as the instrument of living arrangement contained seven items: living alone, living with spouse, living with children, living with grandchildren, living with parents, living with caregiver, and others. The participants were asked how many times they visited their neighbors in the past week. The responses were categorized into four levels: "none," "once a week," "2-3 times a week," and "more than 3 times a week."

The psychological attribute of the housing environment was assessed using the following question: "Are you satisfied with your daily life?" The responses were categorized as "yes" or "no." The Dementia Assessment Sheet for Community-based Integrated Care System-21 items (DASC-21) was used to assess the characteristics of cognition and physical function for the housing environment. The instrument contained 21 questions, and the responses were divided into four levels. Each level was scored from 1 to 4 . The total score was 84 points, and the cut-off point of 31 points was used to identify cognition and physical function impairment. 
Two questions were used to assess the self-assessed housing environment and surrounding housing environment: "Do you think that your house is clean and comfortable?" and "Do you think that the surrounding housing environment is clean and comfortable?" Exposure to the surrounding housing environment was also measured using the following questions: "Is there a factory or waste treatment plant near your house?" "Are factors such as air pollution, noise, low air pressure, humidity, and dryness present around your housing?" The responses were categorized as "yes" or "no."

\section{Depressive symptom measurement}

Depressive symptoms were assessed using the 15-item Geriatric Depression Scale (GDS-15). The GDS-15 was designed as a self- or interviewer-administered screening instrument and consists of 15 questions addressing various depressive symptoms. The 15 questions have been described in detail in a previous study [24]. The optimal cut-off point to identify depressive symptoms was 5 points; $\geq 10$ points indicated moderate to severe depressive symptoms, 5-9 points indicated mild depressive symptoms, and 0-4 points indicated no depressive symptoms among older people [25].

\section{Measurement of other factors}

Social support was assessed using the Chinese version of the Older Americans' Resources and Services questionnaire. The participants' personality characteristics were assessed using the Eysenck Personality Questionnaire (EPQ).

\section{Statistical analysis}

Statistical analysis was restricted to the 938 participants with complete questionnaires and depressive symptom assessment data. Descriptive statistics were used to describe the general characteristics of the study participants.

On the basis of the cut-off values of GDS-15 for distinguishing the degree of depressive symptoms, depressive symptoms as a dependent variable were classified into three categories in accordance with the depressive symptom scores of participants. Chi-square tests were used to perform univariate analysis with the housing environment as an independent categorical variable. Univariate analysis was performed to assess the association between the exposure of housing and surrounding environment and depressive symptoms. The Cochran-Armitage test was used to assess the linear association of depressive symptoms with the levels of exposure to housing and surrounding environment.

We used two separate cumulative logistic regression models to evaluate the association between depressive symptoms and housing environment. Depressive symptom scores were treated as rank variables and added to the cumulative logistic regression model as dependent variables. If the participant's depressive symptom score was less than 5 points, it was expressed as "0" in the dependent variable of the logistic regression model; otherwise, " 1 " if their score is 5 to 9 points and " 2 " if their score is greater or equal to 10 points. In model 1, the variables of the physical environment and the variable of self-assessed housing environment as independent variable were added to the model through a stepwise method. The model was adjusted for the levels of social support, time before falling asleep, and EPQ score. Model 2 included the association of housing environment variables with social, psychological, cognition, and physical function. Both models were also adjusted for age, gender, region, education level, physical activity, income, chronic disease status, eating habits, mobile phone use, sleep time, and income satisfaction.

Binary logistic regression was used to identify the association of factors with the self-assessed housing environment. The significance level for all analyses was set at $P<0.05$. All analyses were performed using SAS for Windows (version 9.4).

\section{Results}

Table 2 shows the characteristics of housing and surrounding environment categorized on the basis of depressive symptom scores. The results of univariate analysis showed that environmental exposure to housing and surrounding risk factors was associated with depressive symptoms.

For the self-assessed housing environment, 0.6, 6.6, and $26.9 \%$ of participants with depressive symptom scores of $<5,5-9$, and $\geq 10$ points responded with "no" when asked "Do you think that your house is clean and comfortable?" respectively. For the physical environment, participants who reported that their house had adequate sunlight exposure, good ventilation, living areas of more than $80 \mathrm{~m}^{2}$, and working shower and who had a residence time of less than 30 years had a significantly lower rate of high depressive symptom scores compared with others. The analysis of social and psychological factors contributing to housing environment showed that participants who lived alone, had poor neighborhood communication, and had low life satisfaction had high depressive symptom scores. For exposure to the surrounding environment, 6.1, 16.7, and $17.3 \%$ of participants with depressive symptom scores of $<5,5-9$, and $\geq$ 10 points responded with "no" when asked "Do you feel clean and comfortable near your house?" respectively. The participants who answered "no" had the highest percentage in the highest category of depressive symptom score. The participants who reported noise or air pollution near their house had high levels of depressive 
Table 2 The depression scores by participants reported the characteristic of housing environment

\begin{tabular}{|c|c|c|c|c|c|c|c|c|}
\hline \multirow[t]{3}{*}{ Variable categories } & \multicolumn{6}{|c|}{ Depression score (points) } & \multirow{3}{*}{$\begin{array}{l}P \\
\text { value }\end{array}$} & \multirow[t]{3}{*}{$P$ for trend } \\
\hline & \multicolumn{2}{|c|}{$<5$} & \multicolumn{2}{|l|}{$5-9$} & \multicolumn{2}{|c|}{$\geq 10$} & & \\
\hline & $\mathrm{n}$ & $\%$ & $\mathrm{n}$ & $\%$ & $\mathrm{n}$ & $\%$ & & \\
\hline \multicolumn{9}{|l|}{ Exposure to housing environment } \\
\hline \multicolumn{9}{|l|}{ Adequate sunshine } \\
\hline Yes & 677 & $(98.2)$ & 180 & $(91.4)$ & 46 & $(88.5)$ & $<0.001$ & $<0.001$ \\
\hline No & 12 & $(1.8)$ & 17 & (8.6) & 6 & $(11.5)$ & & \\
\hline \multicolumn{9}{|l|}{ Good ventilated } \\
\hline Yes & 679 & $(98.5)$ & 186 & $(94.4)$ & 46 & $(88.5)$ & $<0.001$ & $<0.001$ \\
\hline No & 10 & $(1.5)$ & 11 & (5.6) & 6 & $(11.5)$ & & \\
\hline \multicolumn{9}{|l|}{ Living areas $\left(\mathrm{m}^{2}\right)$} \\
\hline$\leq 80$ & 209 & $(30.3)$ & 69 & $(35.0)$ & 28 & $(53.9)$ & 0.001 & 0.001 \\
\hline$>80$ & 480 & $(69.7)$ & 128 & $(65.0)$ & 24 & $(46.1)$ & & \\
\hline \multicolumn{9}{|l|}{ Residence times (yr.) } \\
\hline$\leq 30$ & 320 & $(46.4)$ & 65 & (33.0) & 19 & $(36.5)$ & 0.002 & 0.002 \\
\hline$>30$ & 369 & $(53.6)$ & 132 & $(67.0)$ & 33 & $(63.5)$ & & \\
\hline \multicolumn{9}{|l|}{ Working shower } \\
\hline Yes & 598 & $(86.8)$ & 144 & $(73.1)$ & 45 & $(86.5)$ & $<0.001$ & 0.004 \\
\hline No & 91 & $(13.2)$ & 53 & (26.9) & 7 & $(13.5)$ & & \\
\hline \multicolumn{9}{|l|}{ Living arrangement } \\
\hline Living alone & 546 & $(79.3)$ & 75 & $(38.1)$ & 13 & $(25.0)$ & $<0.001$ & $<0.001$ \\
\hline Living with family or other & 143 & $(20.7)$ & 122 & $(61.9)$ & 39 & $(75.0)$ & & \\
\hline \multicolumn{9}{|l|}{ Neighborhood communication } \\
\hline None & 253 & $(36.7)$ & 81 & $(41.1)$ & 29 & $(55.8)$ & 0.018 & 0.008 \\
\hline At least once a week & 436 & $(63.3)$ & 116 & $(58.9)$ & 23 & $(44.2)$ & & \\
\hline \multicolumn{9}{|l|}{ Life satisfaction } \\
\hline Yes & 677 & $(98.3)$ & 157 & (79.7) & 26 & $(50.0)$ & $<0.001$ & $<0.001$ \\
\hline No & 12 & $(1.7)$ & 40 & (20.3) & 26 & $(50.0)$ & & \\
\hline \multicolumn{9}{|c|}{ Cognitive and physical function (points) } \\
\hline$\leq 30$ & 567 & $(82.3)$ & 83 & $(42.1)$ & 16 & $(30.8)$ & $<0.001$ & $<0.001$ \\
\hline$>30$ & 122 & $(17.7)$ & 114 & $(57.9)$ & 36 & $(69.2)$ & & \\
\hline \multicolumn{9}{|l|}{ Clean and comfortable } \\
\hline Yes & 685 & $(99.4)$ & 184 & (93.4) & 38 & $(73.1)$ & $<0.001$ & $<0.001$ \\
\hline No & 4 & $(0.6)$ & 13 & (6.6) & 14 & $(26.9)$ & & \\
\hline \multicolumn{9}{|c|}{ Exposure to surrounding housing environment } \\
\hline \multicolumn{9}{|l|}{ Air pollution or noise } \\
\hline Yes & 65 & (9.4) & 32 & $(16.2)$ & 11 & $(21.2)$ & 0.002 & $<0.001$ \\
\hline No & 624 & $(90.6)$ & 165 & (83.8) & 41 & (78.8) & & \\
\hline \multicolumn{9}{|l|}{ Clean and comfortable } \\
\hline Yes & 647 & $(93.9)$ & 164 & (83.3) & 43 & $(82.7)$ & $<0.001$ & $<0.001$ \\
\hline No & 42 & $(6.1)$ & 33 & $(16.7)$ & 9 & $(17.3)$ & & \\
\hline
\end{tabular}

symptom scores. The results of the Cochran-Armitage test showed that the depressive symptom scores were linearly negatively associated with adequate sunlight, good ventilation, living areas, working shower, living arrangement, life satisfaction, and self-assessed housing environment and linearly positively associated with residence time and cognitive and physical function scores. 
The odds ratios (ORs) of the housing environment and other related factors for depressive symptoms by separated cumulative logistic regression models are shown in Table 3 . In model 1 , the participants' selfassessed housing environment was strongly negatively associated with levels of depressive symptom scores in the cumulative logistic regression analysis. The OR was 10.75 (95\% CI, 4.39-26.31, $P<0.001$ ) for participants who responded with "no" when asked "Do you think that your house is clean and comfortable?" compared with those who responded with "yes." This association was maintained in model 2 after adjusting for a large number of risk factors, and the OR was 3.47 (95\% CI, 1.14-10.82, $P=0.003$ ). As a physical characteristic of the housing environment, the residence time was positively associated with depressive symptom scores, and the OR was 1.04 (95\% CI, 1.01-1.12, $P=0.042$ ). According to the stepwise regression model, factors such as social support levels, frequency of contact with children, EPQ score, time before falling asleep, and noise and air pollution around the house were associated with the levels of depressive symptom scores. In model 2, low life satisfaction as a psychological characteristic of the housing environment was associated with depressive symptom scores, and the OR was 5.43 (95\% CI, 1.61-6.04, $P<0.001)$. As one attribute of the housing environment, cognitive and physical function was positively associated with depressive symptom scores, and the OR was 1.09 (95\% CI, 1.05-1.14, $P<0.001)$. The level of neighborhood communication, a social attribute of the housing environment, was associated with depressive symptom scores, and the OR was 2.01 (95\% CI, 1.21-3.36, $P<0.001$ ). The model was also adjusted for the use of mobile phones, level of income satisfaction, and housing equipment.

The results of the analysis of related factors for selfassessed housing environment are shown in Table 4 . The self-assessed housing environment conditions were significantly associated with the following environmental factors: good ventilation, working shower, clean and comfortable surrounding environment, levels of cognitive and physical function, social support levels, and time before falling asleep.

Participants who responded with "yes" when asked "Do you think that your house is clean and

Table 3 The odds ratios of housing environment and other related risk factors for depression by cumulative logistic regression models

\begin{tabular}{|c|c|c|c|c|}
\hline \multirow[t]{2}{*}{ Variables } & \multicolumn{3}{|c|}{ Multivariable adjusted } & \multirow{2}{*}{$\begin{array}{l}P \\
\text { value }\end{array}$} \\
\hline & \multirow{2}{*}{ Odd Ratios } & \multicolumn{2}{|c|}{$95 \% \mathrm{Cl}$} & \\
\hline \multicolumn{4}{|c|}{ Model 1} & \\
\hline Do you think that your house is clean and comfortable $(y / n)^{\text {sa }}$ & 10.75 & 4.39 & 26.31 & $<0.001$ \\
\hline Air pollution and noise around house $(n / y)$ pe & 2.72 & 1.41 & 5.25 & 0.002 \\
\hline High levels of social support (points) & 0.81 & 0.75 & 0.88 & $<0.001$ \\
\hline Low frequency of contact with children (weeks) & 1.36 & 1.09 & 1.70 & 0.006 \\
\hline Long time before falling asleep (min) & 1.58 & 1.31 & 1.89 & $<0.001$ \\
\hline Regular physical activity (n/y) & 0.45 & 0.27 & 0.72 & 0.001 \\
\hline High EPQ scores (points) & 1.16 & 1.10 & 1.22 & $<0.001$ \\
\hline \multicolumn{5}{|c|}{ Model 2} \\
\hline Do you think that your house is clean and comfortable $(y / n)^{\text {sa }}$ & 3.47 & 1.14 & 10.82 & 0.003 \\
\hline Long residence times (yr.) ${ }^{\text {pe }}$ & 1.04 & 1.01 & 1.12 & 0.042 \\
\hline Air pollution and noise around house $(\mathrm{n} / \mathrm{y})^{\mathrm{pe}}$ & 3.32 & 1.66 & 8.75 & 0.002 \\
\hline Low life satisfaction $(y / n){ }^{\text {pse }}$ & 5.43 & 1.61 & 6.04 & $<0.001$ \\
\hline Poor cognitive and physical function (points) ${ }^{\text {ce }}$ & 1.09 & 1.05 & 1.14 & $<0.001$ \\
\hline Poor neighborhood communication (times) se & 2.01 & 1.21 & 3.36 & $<0.001$ \\
\hline Living alone ${ }^{\text {se }}$ & 1.44 & 0.60 & 3.49 & 0.340 \\
\hline High levels of social support (points) & 0.82 & 0.73 & 0.92 & $<0.001$ \\
\hline Low frequency of contact with children (weeks) & 1.35 & 1.02 & 1.77 & 0.035 \\
\hline High EPQ scores (points) & 1.16 & 1.10 & 1.24 & $<0.001$ \\
\hline Long time before falling asleep (min) & 1.45 & 1.16 & 1.70 & $<0.001$ \\
\hline
\end{tabular}

sa: self-assessed housing environment

pe: physical attributes of the housing environment

se: social attributes of the housing environment

pse: psychological attribute of housing environment

ce: cognition attribute of housing environment 
Table 4 The effect factors association with the self-assessed housing environment

\begin{tabular}{|c|c|c|c|c|}
\hline \multirow{3}{*}{$\begin{array}{l}\text { Variables } \\
\text { Good ventilated (n/y) }\end{array}$} & \multicolumn{3}{|c|}{ Multivariable adjusted } & \multirow{3}{*}{$\begin{array}{l}P \\
\text { value } \\
0.006\end{array}$} \\
\hline & \multirow{2}{*}{$\begin{array}{l}\text { Odds Ratios } \\
8.28\end{array}$} & \multicolumn{2}{|c|}{$95 \% \mathrm{Cl}$} & \\
\hline & & 1.86 & 12.70 & \\
\hline Working shower (n/y) & 3.82 & 1.30 & 11.28 & $<0.015$ \\
\hline Long time before falling asleep (min) & 0.53 & 0.34 & 0.82 & 0.004 \\
\hline High levels of social support (points) & 1.30 & 1.13 & 1.51 & $<0.001$ \\
\hline Poor cognitive and physical function (points) & 0.11 & 0.04 & 0.29 & $<0.001$ \\
\hline Clean and comfortable surrounding housing environmental $(\mathrm{y} / \mathrm{n})$ & 4.12 & 1.41 & 12.05 & 0.009 \\
\hline
\end{tabular}

Models adjusted for age, gender, region, education level, regular physical activity, income, chronic disease status, habit of food intake, mobile phone use, sleep duration and income satisfaction

comfortable?" were associated with good ventilated (OR 8.28 [95\% CI, 1.86-12.70]), working shower (OR 3.82 [95\% CI, 1.30-11.28]), clean and comfortable surrounding environment (OR 4.12 [95\% CI, 1.41-12.05]), poor cognitive and physical function (OR 9.45 [95\% CI, 3.4425.97]), and high levels of social support (OR 1.30 [95\% CI, 1.13-1.51]).

\section{Discussion}

In the present study, we found that the housing environment was significantly associated with depressive symptoms among older people. We further observed that the housing environment was associated with depressive symptoms based on four attributes: physical, social, psychological, and cognition and physical function. In addition, the self-assessed housing environment was more associated with depressive symptoms than the housing environment based on the four attributes. Clean and comfortable housing environments were strongly negatively associated with depressive symptoms after adjusting for personality characteristics and a number of potential confounding factors. The factors associated with the self-assessed housing environment were identified in the study. Good ventilation, working shower, clean and comfortable surrounding environment, cognitive and physical function, and level of social support were mainly associated with the self-assessed housing environment. In our study, ventilation was significantly associated with the self-assessed housing environment.

\section{Initial research on the housing environment}

Over the past 30 years, several studies have investigated the housing environment in different related fields. The study focus of the housing environment is also changing with the continuous development of society and our understanding of the association between health and the environment. In the past, the housing environment is generally understood as the indoor environment. Studies of housing environment focused on physical and chemical factors such as indoor air constituents, temperature, and humidity [26]. These studies showed that the pollutants in the indoor environment may come from fuel combustion during cooking, heating, smoking, and construction, and ventilation is necessary to reduce concentrations of pollutants generated indoors [27].

\section{Physical function and housing environment}

Due to the progression of medical technology, the life expectancy has increased. Moreover, the number of physically challenged and disabled older people is also increasing. Falls have become a public health problem for older people. The focus of study on the housing environment has gradually shifted from physical attributes to fall prevention and barrier-free housing design [28, 29]. Some studies have explored how to improve the housing environment to help older people adapt to the decline of functional ability, thereby reducing the prevalence of anxiety and depression and maintaining happiness and independence in daily life. However, there is limited evidence to evaluate the association between adaptability of individual physical function for housing environment and depression [30,31]. The results of the present study showed that the level of physical function of participants was positively associated with their selfassessed housing environment, and those who reported that their houses were comfortable and tidy had low depressive symptom scores.

\section{Social, psychological, and housing environment}

With the rapid development of society and the economy, relationship problems among family members may occur. An increasing number of researchers are interested in studying the social attributes of the housing environment caused by the number of empty nesters. In addition, the number of older people living alone is increasing. Previous studies have shown that elderly individuals who live alone are associated with an increased risk for depressive symptoms [23, 32-34]. In the present study, we further found that adequate social support can improve the increased risk of depressive symptoms due to living arrangements as the living arrangement was no longer statistically significant in the model. In addition, 
the study on the social attributes of the housing environment includes the effect of neighborhood communication and economic differences on mental health outcomes [35-37]. Recently, studies on residential satisfaction and well-being, which are psychological attributes of the housing environment, have been widely conducted [38, 39]. However, some important risk factors, such as personality factor, are rarely considered. In the present study, we used the EPQ scale to assess the personality characteristics of participants, and the association between housing environment factors and depressive symptoms was adjusted using the EPQ score to remove the effect of the important risk factor. However, previous studies have not comprehensively explored the association between multiple attributes of the housing environment and depressive symptoms among older people. Previous analyses lacked evaluation models to make an objective assessment of depressive symptom risks. Evidence on how to improve the housing environment of older people, promote mental health, and reduce the prevalence of depressive symptoms is also lacking.

\section{Conduct studies on the housing environment}

To our knowledge, no studies have used cognitive function as an attribute of the housing environment to evaluate the association between housing environment and depressive symptoms. In addition, whether individuals have a correct understanding and perception for the housing environment has not been considered when evaluating the association between housing environment and depressive symptoms. Our results showed that the cognitive function level is positively associated with the perceived assessment of the housing environment. Individuals with high cognitive level have high adaptability and high evaluation for their living housing environment, and those with high evaluation for their living housing environment are associated with lower risk of depressive symptoms. In this study, we not only assessed the association between housing environment and depressive symptoms in terms of physical, social, and psychological attributes, but also assessed the association between depressive symptoms and housing environment in terms of cognitive function.

\section{Suggestions}

With aging, older people become more vulnerable to environmental challenges and depression. More older people will spend their time in their own houses. The housing environment is particularly important for the well-being of older people, especially mental health. With the large amount of time spent in the house, the housing environment is a potential important factor for increasing and improving the prevalence of depressive symptoms. Many countries are planning and preparing to implement housing assistance programs around the world $[40,41]$. However, there is no reliable evidence on how to reduce depressive symptoms in older people by improving the housing environment. Apartments or home for the aged is an important location for older people to live in their later years. The housing environment can promote the mental health of older people, but it can also lead to severe depressive symptoms. Our results suggest that to improve the housing environment and develop intervention strategies of depressive symptoms, we must consider the attributes of the housing environment and adopt comprehensive intervention strategies centered on the physical environment, social environment, psychological environment, and cognitive and physical functions, so that older people can successfully avoid depressive symptoms and live at home healthily. We can use accessible resources to improve the adaptability between individuals and housing environment.

\section{Limitations}

The present study has one major limitation that must be addressed. This was a cross-sectional design. The associations between depressive symptoms and housing environment from multiple dimensions were observed, but the causality could not be discussed. This complex and changing trend of environmental factors and the risk of depressive symptoms over time cannot be evaluated and observed. In addition, compared with the measured housing environment, the self-assessed housing environment is more associated to depressive symptoms; therefore, the negative assessment could be a result of the depressive state of mind, which can lead to reporting bias.

\section{Conclusions}

The housing environment has an important impact on depressive symptoms. This study indicates that depressive symptoms are significantly associated with the housing environment from several aspects, including physical, social, and psychological. Correct cognition of the housing environment and adaptability of physical function to the housing environment as an attribute of the housing environment are also associated with depressive symptoms. In addition, although our study fully considered the housing environment variables and important risk factors from multiple dimensions, we could not obtain a large enough sample size to evaluate the interactions between several dimensions of housing environment and depressive symptoms. This study suggests that the association between housing environment and depression symptoms is complex. A longitudinal study design is needed to confirm the causality of these factors in the future. 


\section{Abbreviations}

DASC-21: Dementia Assessment Sheet for Community-based Integrated Care System-21 items; OARS: Older American Resources and Services; EPQ: Eysenck Personality Questionnaire; GDS-15: 15-item Geriatric Depression Scale; ORs: Odds ratios; Cl: Confidence interval

\section{Acknowledgements}

We thank Xia Gao, Songsong Han, Dongbin Hu and Xuanting Liu for their assistance with survey set up.

\section{Authors' contributions}

In this paper, $Y L$ and $Y C$ were the principal investigators and involved in the study design and conception, manuscript preparation. PYC, YYP, YXL and NWL performed data collection and analysis. All authors read and approved the final manuscript.

\section{Funding}

This work was supported by the basic public welfare project of Zhejiang Province (LGF19H260012), and in part by Weiliang Special Foundation, Zhejiang University School of Public Health. These foundations provided financial support for this study.

\section{Availability of data and materials}

The datasets used and/or analyzed during the current study are available from the corresponding author on reasonable request.

\section{Declarations}

\section{Ethics approval and consent to participate}

All participants provided written informed consent before participation. The study was approved by the institutional review board at the School of Public Health, Zhejiang University (No: ZGL201909-10).

\section{Consent for publication}

Not applicable.

\section{Competing interests}

The authors declare no conflict of interest.

\section{Received: 9 November 2020 Accepted: 8 April 2021}

\section{Published online: 17 April 2021}

\section{References}

1. Friedrich MJ. Depression is the leading cause of disability around the world. JAMA. 2017;317(15):1517. https://doi.org/10.1001/jama.2017.3826.

2. Pilania M, Yadav V, Bairwa M, Behera P, Gupta SD, Khurana H, et al. Prevalence of depression among the elderly ( 60 years and above) population in India, 1997-2016: a systematic review and meta-analysis. BMC Public Health. 2019;19(1):832. https://doi.org/10.1186/s12889-019-7136-z.

3. Arumugam B, Nagalingam S, Nivetha R. Geriatric depression among rural and urban slum community in Chennai - a cross sectional study. J Evol Med Dent Sci. 2013;2(7):795-801. https://doi.org/10.14260/jemds/340.

4. Mathias K, Goicolea I, Kermode M, Singh L, Shidhaye R, San SM. Crosssectional study of depression and help-seeking in Uttarakhand. North India BMJ Open. 2005;5(11):e008992. https://doi.org/10.1136/bmjopen-2015008992.

5. Carney RM, Freedland KE. Depression and coronary heart disease. Nat Rev Cardiol. 2017;14(3):145-55. https://doi.org/10.1161/CIRCULATIONAHA.108.1 90769.

6. Lichtman JH, Froelicher ES, Blumenthal JA, Carney RM, Doering LV, FrasureSmith $\mathrm{N}$, et al. Depression as a risk factor for poor prognosis among patients with acute coronary syndrome: systematic review and recommendations: a scientific statement from the American Heart Association. Circulation. 2014;129(12):1350-69. https://doi.org/10.1161/CIR. 0000000000000019 .

7. Almeida OP, Alfonso H, Flicker L, Hankey GJ, Norman PE. Cardiovascular disease, depression and mortality: the health in men study. Am J Geriatr Psychiatry. 2012;20(5):433-40. https://doi.org/10.1097/JGP.0b013 e318211cled.
8. Zhang YX, Chen YJ, Ma LN. Depression and cardiovascular disease in elderly: current understanding. J Clin Neurosci. 2018;47:1-5. https://doi.org/10.1016/ j.jocn.2017.09.022.

9. Noël PH, Williams JW, Unützer J, Worchel J, Lee S, John CJ. Depression and comorbid illness in elderly primary care patients: impact on multiple domains of health status and well-being. Ann Fam Med. 2004;2(6):555-62. https://doi.org/10.1370/afm.143.

10. Kessler RC, Amminger GP, Aguilar-Gaxiola S, Alonso J, Lee S, Ustün TB. Age of onset of mental disorders: a review of recent literature. Curr Opin Psychiatry. 2007;20(4):359-64. https://doi.org/10.1097/YCO.0b013e3281 6ebc8c.

11. Kaiser ML, Hand MD, Pence EK. Individual and community engagement in response to environmental challenges experienced in four low-income urban neighborhoods. Int J Environ Res Public Health. 2020;17(6):1831. https://doi.org/10.3390/ijerph17061831.

12. Klijs B, Kibele EUB, Ellwardt L, Zuidersma M, Stolk RP, Wittek RPM. Neighborhood income and major depressive disorder in a large Dutch population: results from the life lines cohort study. BMC Public Health. 2016; 16(1):773. https://doi.org/10.1186/s12889-016-3332-2.

13. Meng $X$, D'Arcy C. The projected effect of increasing physical activity on reducing the prevalence of common mental disorders among Canadian men and women: a national population-based community study. Prev Med. 2013;56(1):59-63. https://doi.org/10.1016/j.ypmed.2012.11.014.

14. Fu TS, Lee CS, Gunnell D, Lee WC, Cheng ATA. Changing trends in the prevalence of common mental disorders in Taiwan: a 20-year repeated cross sectional survey. Lancet. 2013;381(9862):235-41. https://doi.org/10.101 6/S0140-6736(12)61264-1.

15. Mendenhall E, Kohrt BA, Norris SA, Ndetei D, Prabhakaran D. Noncommunicable disease syndemics: poverty, depression, and diabetes among low-income populations. Lancet. 2017;389(10072):951-63. https:// doi.org/10.1016/S0140-6736(17)30402-6.

16. Zuelke AE, Luck T, Schroeter ML, Witte AV, Hinz A, Engel C, et al. The association between unemployment and depression results from the population-based LIFE-adult-study. J Affect Disord. 2018;235:399-406. https://doi.org/10.1016/j.jad.2018.04.073.

17. Fournier JC, DeRubeis RJ, Hollon SD, Dimidjian S, Amsterdam JD, Shelton RC. Antidepressant drug effects and depression severity: a patient-level metaanalysis. JAMA. 2010;303(1):47-53. https:/doi.org/10.1001/jama.2009.1943.

18. Bowling A, Stafford M. How do objective and subjective assessments of neighbourhood influence social and physical functioning in older age? Findings from a British survey of ageing. Soc Sci Med. 2007;64(12):2533-49. https://doi.org/10.1016/.socscimed.2007.03.009.

19. Oswald F, Wahl HW, Schilling O, Nygren C, Fänge A, Sixsmith A, et al. Relationships between housing and healthy aging in very old age. Gerontologist. 2007;47(1):96-107. https://doi.org/10.1093/geront/47.1.96.

20. Wahl H-W, Schilling O, Oswald F, Iwarsson S. The home environment and quality of life-related outcomes in advanced old age: findings of the ENABLE-AGE project. Eur J Ageing. 2009;6(2):101-11. https://doi.org/10.1007/ s10433-009-0114-z.

21. Fänge A, Iwarsson S. Physical housing environment: development of a selfassessment instrument. Can J Occup Ther. 1999;66(5):250-60. https://doi. org/10.1177/000841749906600507.

22. Schilling OK. Cohort- and age-related decline in elder's life satisfaction: is there really a paradox? Eur J Ageing. 2005;2(4):254-63. https://doi.org/10.1 007/s10433-005-0016-7.

23. Zhang Y, Liu ZF, Zhang LL, Zhu PY, Wang X, Huang YX. Association of living arrangements with depressive symptoms among older adults in China: a cross-sectional study. BMC Public Health. 2019;19(1):1017. https://doi.org/1 0.1186/s12889-019-7350-8.

24. Jerome A, Yesavage MD, Javaid I, Sheikh MD. Criterion-based validity and reliability of the geriatric depression screening scale (GDS-15) in a large validation sample of community-living Asian older adults. Aging Ment Health. 2009;13(3):376-82. https://doi.org/10.1080/13607860902861027.

25. Shin C, Park MH, Lee SH, Ko YH, Kim YK, Han KM, et al. Usefulness of the 15item geriatric depression scale (GDS-15) for classifying minor and major depressive disorders among community-dwelling elders. J Affect Disord. 2019;259:370-5. https://doi.org/10.1016/j.jad.2019.08.053.

26. Sundell J, Levin H, Nazaroff WW, Cain WS, Fisk WJ, Grimsrud DT, et al. Ventilation rates and health: multidisciplinary review of the scientific literature. Indoor Air. 2001;2(3):191-204. https://doi.org/10.1111/j.1600-0668.2 010.00703.x. 
27. Xu X, Weisel CP. Human respiratory uptake of chloroform and haloketones during showering. J Expo Anal Environ Epidemiol. 2005;15(1):6-16. https:// doi.org/10.1038/sj.jea.7500374.

28. Lord S, Menz H, Sherrington C. Home environment risk factors for falls in older people and the efficacy of home modifications. Age Ageing. 2006;35: 55-9. https://doi.org/10.1093/ageing/afl088.

29. Clemson L, Mackenzie L, Ballinger C, Close J, Cumming R. Environmental interventions to prevent falls in community-dwelling older people a metaanalysis of randomized trials. J Aging Health. 2008;20(8):954-71. https://doi. org/10.1177/0898264308324672.

30. Gitlin LN, Winter L, Dennis MP, Corcoran M, Schinfeld S, Hauck WW. A randomized trial of multicomponent home intervention to reduce functional difficulties in older adults. J Am Geriatr Soc. 2006;54(5):809-81. https://doi.org/10.1111/j.1532-5415.2006.00703.x.

31. Spillman BC. Changes in elderly disability rates and the implications for health care utilization and cost. Milbank Q. 2004;82:157-94. https://doi.org/1 0.1111/j.0887-378X.2004.00305.X.

32. Fukunaga R, Abe Y, Nakagawa Y, Koyama A, Fujise N, Ikeda M. Living alone is associated with depression among the elderly in a rural community in Japan. Psychogeriatrics. 2012;12(3):179-85. https://doi.org/10.1111/j.1479-83 01.2012.00402.x.

33. Stahl ST, Beach SR, Musa D, Schulz R. Living alone and depression: the modifying role of the perceived neighborhood environment. Aging Ment Health. 2017;21(10):1065-71. https://doi.org/10.1080/13607863.2016.1191060.

34. Hoon Oh D, Park JH, Lee HY, Ah Kim S, Choi BY, Nam JH. Association between living arrangements and depressive symptoms among older women and men in South Korea. Soc Psychiatry Psychiatr Epidemiol. 2015; 50(1):133-41. https://doi.org/10.1007/s00127-014-0904-2.

35. Friesinger JG, Topor A, Bøe TD, Larsen IB. Studies regarding supported housing and the built environment for people with mental health problems: a mixed-methods literature review. Health Place. 2019;57:44-53. https://doi.org/10.1016/j.healthplace.2019.03.006.

36. Haseda M, Kondo N, Takagi D, Kondoc K. Community social capital and inequality in depressive symptoms among older Japanese adults: a multilevel study. Health Place. 2018;52:8-17. https://doi.org/10.1016/j.hea Ithplace.2018.04.010.

37. James P. Hart JE, Banay RF, Laden F, Signorello LB. Built environment and depression in low-income African Americans and whites. Am J Prev Med. 2017;52(1):74-84. https://doi.org/10.1016/j.amepre.2016.08.022.

38. Tran TQ, Van Vu H. A microeconometric analysis of housing and life satisfaction among the Vietnamese elderly. Qual Quant. 2018;52(2):849-67. https://doi.org/10.1007/s11135-017-0492-9.

39. Cho SH, Lee TK, Kim JT. Residents' satisfaction of indoor environmental quality in their old apartment homes. Indoor Built Environ. 2011;20:16-25. https://doi.org/10.1177/1420326X10392010.

40. Watson DP, Ahonen EQ Shuman V, Brown M, Tsemberis S, Huynh P, et al. The housing first technical assistance and training (HFTAT) implementation strategy: outcomes from a mixed methods study of three programs. Subst Abuse Treat Prev Policy. 2018;13(1):32. https://doi.org/10.1186/s13011-018-01 72-3.

41. Fenelon A, Mayne P, Simon AE, Rossen LM, Helms V, Lloyd P, et al. Housing assistance programs and adult health in the United States. Am J Public Health. 2017;107(4):571-8. https://doi.org/10.2105/AJPH.2016.303649

\section{Publisher's Note}

Springer Nature remains neutral with regard to jurisdictional claims in published maps and institutional affiliations.

Ready to submit your research? Choose BMC and benefit from:
- fast, convenient online submission
- thorough peer review by experienced researchers in your field
- rapid publication on acceptance
- support for research data, including large and complex data types
- gold Open Access which fosters wider collaboration and increased citations
- maximum visibility for your research: over 100M website views per year
At BMC, research is always in progress.
Learn more biomedcentral.com/submissions

